\title{
Corporate Social Responsibility and Brand Image: An Empirical Investigation of Private Sector Hospitals in Saudi Arabia
}

\author{
Ala'Eddin Mohammad Khalaf Ahmad ${ }^{1}$, Omar Zayyan Alsharqi ${ }^{1}$, Hussein Mohammad Al-Borie ${ }^{1}$, Mowaffag Mohammed \\ Ashoor $^{2}$, Abdulkaream Saeed Al-Orige ${ }^{3}$ \\ ${ }^{1}$ Faculty of Economics and Administration, King AbdulAziz University, Jeddah, Saudi Arabia \\ ${ }^{2}$ Saudi Airlines Medical Services, Jeddah, Saudi Arabia \\ ${ }^{3}$ Ministry of Health, Jeddah, Saudi Arabia \\ Correspondence: Ala'Eddin Mohammad Khalaf Ahmad, Faculty of Economics and Administration, King Abdul Aziz \\ University, Jeddah, Saudi Arabia. E-mail: amahmed1@kau.edu.sa or aladdin.a.h@ hotmail.com
}

Received: June 20, 2016

doi:10.5539/ibr.v9n9p91
Accepted: July 4, $2016 \quad$ Online Published: July 27, 2016

URL: http://dx.doi.org/10.5539/ibr.v9n9p91

\begin{abstract}
The purpose of this paper is to investigate the impact of CSR on brand image of private hospitals in Jeddah city, Saudi Arabia. A purposive sampling technique was employed to recruit 187 managers in different positions representing the desired range of demographic characteristics (e.g. gender, age, nationality, and job position). This research showed that CSR dimensions (vision and workplace) had a positive effect on brand image of the private hospitals on one hand. On the other hand, other dimensions (community relations, marketplace and accountability) had a negative effect on brand image. The paper contributes to previous research by adding to existing knowledge regarding CSR and brand image of the hospitals. The paper makes key recommendations towards adoption of CSR among hospitals.
\end{abstract}

Keywords: CSR, brand image, hospitals, Saudi Arabia

\section{Introduction}

Globalization as a concept has introduced an ever-increasing number of social obligations for business organizations. Throughout the world, corporate social responsibility (CSR) stems from a commitment to the society in which a business operates. CSR has enormous potential for strengthening society. Among the organizations which should adopt CSR are hospitals. CSR has become one of the central issues on the agendas of organizations today, but is still a long way from being centre-stage in corporate strategy (Stewart, 2006). One of the key problems is that the impact of CSR on competitiveness has not yet been fully understood (Porter and Kramer, 2006). Significant amounts of research have been conducted in the area of analysis of how CSR relates to financial performance (Chand and Fraser, 2006; McWilliams and Siegel, 2001).CSR becomes a very relevant idea through such exploration, as it is one of the main themes in the debate on the business's role and its duty towards society. CSR has been defined as: the integration of business operations and values, ensuring that environmental concerns are embedded into organizational strategy and action, along with stakeholders' requirements, including customers, employees and investors (Smith, 2003, p.42). CSR is: the obligation which an organization has to introduce benefits to society as a whole in the way it uses its resources through committed sharing and involvement in society, regardless of simple profit gains for the organization (Porter and Kramer, 2006). Any attempt at conceptualizing the term CSR should, at some stage, involve an attempt to answer certain questions, such as what are the main factors in building CSR at the hospitals, which influence the hospital? The research problem evolves around investigating the factors of CSR in Saudi private sector hospitals, and how these factors influence hospital image. The current research answers the following question: What are the main factors which constitute corporate social responsibility and how do these factors influence brand image in Saudi private sector hospitals? This research aims to investigate the impact of CSR on brand image in private sector hospitals in Jeddah city, Saudi Arabia.

\section{Literature Review}

This section seeks to describe the theoretical background associated to CSR in the health services industry. Moreover, it seeks to represent a background about all variables related to the research. CSR has become a very important issue on organizational agendas today, though it is by no means Centre-stage in corporate strategy (Stewart, 2006). One of the key problems is the lack of understanding about the impact CSR has on organizational image (Porter and Kramer, 2006). 
Defining CSR is one of the frames of reference that tries to shed light on the role business should play in society. In research and theory building, CSR is approached from different perspectives, such as social performance (Swanson, 1995), business ethics (Solomon, 1993), corporate governance (Freeman and Evans, 1990), social contract (Donaldson and Dunfee, 2002), management of interested parties (Donaldson and Preston, 1995; Lozano, 2002), corporate citizenship (Waddock, 2000; Zadek, 2001), and accountability (Valor, 2005). CSR can be defined as the means by which a business voluntarily integrates social and environmental issues into its day-to-day functions and into its interaction with stakeholders (European Commission, 2002). The problem with that definition is that no widely accepted integrated framework exists (1995) which clearly identifies social and environmental issues, how these can be integrated by an organization into its processes and relationships and, in particular, how to achieve all this strategically (Porter and Kramer, 2006). Various CSR schemes vary in their use of terminology, classifications and definitions, but as shown in the following, it is proposed that CSR issues can be grouped into five dimensions:

(1) Vision, including the development of CSR ideas in the business, governance, codes of ethics, standards and reputation (Carter et al., 2003).

(2) Societal interactions, such as affiliations with various stakeholders, corporate philanthropy and community action (Freeman, 1999).

(3) Workplace, including labor practices and human rights issues (European Commission, 2002; International Labor Organization, 2007).

(4) Accountability, including corporate transparency, reporting and communication (Global Reporting Initiative, 2002).

(5) Marketplace, including CSR practices directly related to core business activities such as research and development, pricing, fair competition, marketing or investment (Whetten et al., 2001).

CSR proponents consider that organizations should apply these five dimensions of CSR (Jones and Wicks, 1999). However, it has been argued that often CSR is seen simply as a cosmetic effort by organizations due to calls from society (Porter and Kramer, 2006). An important aspect of the CSR agenda currently is the difference between cosmetic and strategic approaches to CSR, given that many organizations could be accused of only looking at CSR in terms of their own reputation, even though it is portrayed theoretically as a crucial business issue with significant impact throughout the organization and its functions (Porter and Kramer, 2006). One of the key management questions in that debate is whether implementing CSR affects a firm's competitiveness (Porter and Kramer, 2006). Defining competitiveness is a multidimensional concept that can be used at country, industry and firm levels (Ambastha and Momaya, 2004). In general, terms, competitiveness is described as the strength of an organization in comparison to its competitors. Traditionally, many authors have considered productivity as a good indicator of competitiveness in an organization (Porter and Kramer, 2006). However, according to McKinsey, the idea of tangible performance measurement is insufficient, as it ignores key competitiveness-generating resources in the form of intangible capital such as knowledge, relationships, reputation or talent (Lowell, 2007). Image is described as a good indicator of competitiveness at an organization level, including corporate branding in terms of building trust and reputation in the relationship with stakeholders. Therefore, it is hypothesized that CSR has positive effect on brand image. The research hypotheses formulated as the following:

There is a significant relationship between CSR and brand image in Saudi private sector hospitals in Jeddah city. The research sub-hypotheses are the following:

1- There is a significant relationship between hospital vision and brand image in Saudi private sector hospitals in Jeddah city.

2- There is a significant relationship between community relations and brand image in Saudi private sector hospitals in Jeddah city.

3- There is a significant relationship between workplace and brand image in Saudi private sector hospitals in Jeddah city.

4- There is a significant relationship between accountability and brand image in Saudi private sector hospitals in Jeddah city.

5- There is a significant relationship between marketplace and brand image in Saudi private sector hospitals in Jeddah city.

\section{Rationale of the Research}

This research seeks to make an original contribution to knowledge by investigating the CSR factors influencing brand image in Saudi Arabia. This research will contribute to the health services sector and social responsibility in finding out the role of these factors (vision, community relations, workplace, accountability, and marketplace) in delivering a better health service within the health service sector. This research paper tries to contribute to the health organizations by considering at the impact of CSR elements on hospital image. This research deals with ignored area in KSA, which is the health marketing and social responsibility of health services. It is considered new research in the diffusion of marketing in the area of services to gain an 
understanding of the private hospital relevance influence, and the contribution of these factors to Saudi hospitals; such a contribution will be favorable equally academically and professionally. Scholastically, this research paper aims to emphasis academic consideration upon ignored field. Professionally, health executives will similarly look at the practical implications of such effort and the opportunity of executing the implications of this study in their authentic relationships with their stakeholders.

\section{Research Objectives}

This research aims to:

1- Identify the main factors, which constitute CSR at private sector hospitals in Jeddah city, Saudi Arabia.

2- Investigate the effect of certain factors (vision, community relations, workplace, accountability, and marketplace) on the image of Saudi private sector hospitals in Jeddah city, Saudi Arabia.

\section{Research Methodology}

This type of research is a cross-sectional research survey in which all the general private hospitals operating in the Jeddah health market were included. It is a single cross-sectional design, in which the collection of information from research population and respondents was performed once only. This research aimed to investigate the effect of factors (hospital vision, community relations, workplace, accountability, and marketplace) on the brand image in Saudi private sector hospitals. This research is a descriptive analytical study that describes the nature of the relationship between the CSR elements and the brand image in Saudi private sector hospitals in Jeddah city. The research population consists of the private hospitals in Jeddah city. The population in this research is defined as all the hospitals of the Jeddah governorates in the Western Region, which are licensed as general private hospitals by the Ministry of Health. The number of hospitals included in the research population for this study was 34 hospitals. These were classified according to size. The hospitals were classified according to the number of available beds: large hospitals ( 300 or more than beds), medium hospitals (150-299 beds), and small hospitals (less than150beds).The current research chooses hospitals which have inpatient bed capacity of 100 beds plus, and the total number of hospitals chosen was 11 hospitals. These hypotheses were formulated inductively from the researcher's observation and from the literature. The descriptive part needed to describe and identify the research factors, which constitute factors influencing brand image in private sector hospitals in Jeddah (Creswell, 2003).In the analytical part, the research model is tested through examining the impact of CSR on brand image in Saudi private sector hospitals, in order to search how far the CSR components will affect image for these hospitals.

\subsection{The Research Respondents}

The research was conducted with the senior management teams in the Jeddah private hospitals. These teams include the following: general director, medical manager, administrative manager, nursing manager, marketing manager, public relations manager, clinics manager, and heads of medical and administrative departments. The research respondents consist of 292 staff, and the researcher took all of them as a purposive research sample. The research retrieved 187 valid questionnaires, which represents $64 \%$.

\subsection{Data Collection}

The research questionnaire was designed based on previous empirical literature, and based on interviews with hospital managers within the pilot study. The research questionnaire was used as primary data collection method as shown in Table 1. The components of CSR and brand image items were measured on a 5-point Likert-scale ranging from five (strongly agree) to one (strongly disagree). For the CSR and brand image dimensions, the research respondents were asked to indicate the degree of agreement or disagreement on the CSR items that hospitals used in order to achieve brand image of the hospital. Multiple dimensions offered assessment of measurement properties. Consistent with the literature, the scale items selected for the dependent variable were direct measures of brand image with influences received from adoption of CSR as independent variables. This is a recommended format for surveys in marketing and social responsibility. 
Table 1. CSR factors: Independent variables (vision, community relations, workplace, accountability, and marketplace in Saudi private hospitals were measured on:

\begin{tabular}{l} 
Vision: Adopting continuous quality improvement; Focus on applying the medical ethics code; Building \\
profitable values for our stakeholders. \\
\hline Community Relations: Conducting free medical days; Donating money to local charities; Conducting health \\
promotion and educational campaigns; Supporting cultural activities; Engaging in partnership and collaboration \\
with different stakeholders (e.g. general directorates of civil defense). \\
Workplace: Applying human rights concepts (e.g. EEO); Building good relations between staff; Providing an \\
equitable salary system; Improving psychological climate at work; Engaging in open, honest, and flexible \\
communication with employees; Involving employees in decision-making processes. \\
\hline Marketplace: Implementing a procedure to handle patient/consumer complaints; Providing truthful and honest \\
information to the patient; Avoiding false and misleading advertising and sales promotions that use deception or \\
manipulation; Fair competition; Health service research and development for new health solutions. \\
\hline Accountability: Adopting corporate transparency; Adopting medical negligence responsibility. \\
\hline Brand Image: As dependent variable; Our hospital builds a good trust; our hospital builds a good reputation.
\end{tabular}

\section{Analytical Approach}

The basic hypothesis conceives that CSR factors influence brand image in Saudi private sector hospitals in Jeddah city. To test this relationship, the researcher employed a multiple regression model.

\subsection{Demographic Data Results}

Table 2. Frequency and Percentage for Demographic Information

\begin{tabular}{|c|c|c|c|}
\hline & & Frequency & Percentage \\
\hline \multirow[t]{3}{*}{ Gender } & Male & 155 & 82.8 \\
\hline & Female & 32 & 17.2 \\
\hline & Total & 187 & 100.0 \\
\hline \multirow[t]{3}{*}{ Nationality } & Saudi & 109 & 58.3 \\
\hline & Non-Saudi & 78 & 41.7 \\
\hline & Total & 187 & 100.0 \\
\hline \multirow[t]{5}{*}{ Age } & Under 30 & 11 & 5.8 \\
\hline & $30-40$ & 33 & 17.6 \\
\hline & $41-50$ & 76 & 40.6 \\
\hline & Above 50 & 67 & 35.8 \\
\hline & Total & 187 & 100.0 \\
\hline \multirow[t]{6}{*}{ Experience } & Less than 5 & 13 & 6.9 \\
\hline & $5-9$ & 24 & 12.8 \\
\hline & $10-15$ & 46 & 24.5 \\
\hline & $16-20$ & 90 & 48.1 \\
\hline & Above 20 & 14 & 7.4 \\
\hline & Total & 187 & 100.0 \\
\hline \multirow[t]{4}{*}{ Education } & Diploma or less & 12 & 6.4 \\
\hline & Bachelor & 109 & 58.2 \\
\hline & Postgraduate & 66 & 35.2 \\
\hline & Total & 187 & 100.0 \\
\hline \multirow[t]{9}{*}{ Position } & General manager & 3 & 1.6 \\
\hline & Medical manager & 7 & 3.7 \\
\hline & Administrative manager & 9 & 4.8 \\
\hline & Marketing manager & 3 & 1.6 \\
\hline & Outpatients clinic manager & 8 & 4.2 \\
\hline & General relationship manager & 9 & 4.8 \\
\hline & Administrative department manager & 76 & 40.6 \\
\hline & Medical department manager & 72 & 38.5 \\
\hline & Total & 187 & 100.0 \\
\hline \multirow[t]{4}{*}{ Hospital Size } & Small & 60 & 32.0 \\
\hline & Medium & 73 & 39.0 \\
\hline & Large & 54 & 28.8 \\
\hline & Total & 187 & 100.0 \\
\hline
\end{tabular}

Table 2 shows that:

1. The percentage for "Gender" reached $82.8 \%$ for male, but the percentage for female reached $17.2 \%$.

2. The percentage for "Nationality" reached $58.3 \%$ for Saudi, but the percentage for Non-Saudi reached $41.7 \%$.

3. The highest percentage for "Age" reached $40.6 \%$ for age category $41-50$ years, but the lowest percentage reached $5.8 \%$ for age category under 30 . 
4. The highest percentage for "Experience" reached $48.1 \%$ for $16-20$ years' experience, but the lowest percentage reached $6.9 \%$ for Less than 5 years.

5. The highest percentage for "Education" reached $58.2 \%$ for Bachelor holders, but the lowest percentage reached $6.4 \%$ for Diploma holders.

6. The highest percentage for "Position" reached 40.6\% for Administrative department manager, but the lowest percentage reached $1.6 \%$ for General manager and Marketing manager.

7. The highest percentage for "Hospital size" reached 39\% for Medium, but the lowest percentage reached $28.8 \%$ for Large.

To test the general hypothesis, multiple regression was applied. Table 3 shows that:

Table 3. Result of regression for relationship between corporate social responsibility and hospital image

\begin{tabular}{llllllll}
\hline Independent variables & Beta & T & Sig. & R & R Square & F & Sig. \\
\hline Vision & 0.26 & 4.46 & 0.04 & & & & \\
Community relations & 0.46 & 8.48 & 0.09 & & & & \\
Workplace & 0.11 & 2.16 & 0.03 & 0.86 & 0.73 & 210.89 & 0.00 \\
Marketplace & 0.28 & 5.10 & 0.08 & & & & \\
Accountability & 0.26 & 4.46 & 0.13 & & & & \\
$\quad$ Dependent variable: Brand image & & & & & \\
\hline
\end{tabular}

Table 3 shows that:

1. Corporate social responsibility has a positive significant influence on brand image in Saudi private hospitals in Jeddah city. Where the values of ( $R, R$ Square, F) reached $(0.86,0.73,210.89)$, Sig. (0.00). Therefore, the general hypothesis is accepted.

2. There is a significant relationship between hospital vision and brand image in Saudi private sector hospitals in Jeddah city. Where the values of (Beta, T) reached $(0.26 ; 4.46)$, Sig. $(0.04)$. Therefore, the second hypothesis is accepted.

3. The community relations have a positive significant influence on brand image in Saudi private hospitals. Where the values of (Beta, T) reached (0.46; 8.48), Sig. (0. 09). Therefore, the third hypothesis is rejected.

4. The workplace has a positive significant influence on brand image in Saudi private hospitals. Where the values of (Beta, T) reached $(0.11 ; 2.16)$, Sig. $(0.03)$. Therefore, the fourth hypothesis is accepted.

5. The marketplace has a positive significant influence on brand image in Saudi private hospitals. Where the values of (Beta, T) reached $(0.28,5.10)$, Sig. (0.08). Therefore, the fifth hypothesis is rejected.

6. The accountability has a positive significant influence on brand image in Saudi private hospitals. Where the values of (Beta, T) reached $(0.26,4.46)$, Sig. (0.13). Therefore, the sixth hypothesis is rejected.

\section{Research Discussion}

This section aims to discuss the findings and results that have emerged from the data analysis presented in the research analysis. In addition, comparisons are made with other related studies in literature. Empirically, the model assumed that CSR components have an impact on brand image. It additionally predicted that the impact of such components on brand image would differ according to the demographic variables, i.e. age, gender, education, and experience. One-hundred-and-eighty-seven staff from different private hospitals in Jeddah city were included in this research. The research sample consists of males and females, with the males accounting for approximately eighty percent and the rest of the ratio being females. Analysis shows that the vision has significant influences on hospital image, result which is consistent with the Vilanova et al. (2009) study, where they found that good vision helps an organization to build good profitability and image in its marketplace. As such, it is considered a crucial component of CSR. The community relations in this study were insignificant. The researcher found that there is an insignificant relationship between community relations and hospital image. The results are supported by Vilanova et al. (2009) who found that community relations are not supported by management teams. Workplace in this study was significant. However, Vilanova et al. (2009) were coincident with the significance of workplace as a major component of corporate social responsibility. Vilanova et al. (2009) agree with this research, as workplace is a significant positive influence on hospital image. The marketplace in this study was insignificant. The researcher found that there is an insignificant relationship between marketplace and hospital image. Finally, accountability was insignificant in this study.

\section{Research Conclusion}

Vision is considered as one of the most influential elements on brand image in Saudi private sector hospitals in Jeddah city. This is because of the attention paid by hospital management teams to continuous development within the 
organization, and the application of ethical codes criteria and values. Community relations are an insignificant influential element on hospital image. This may be caused by different reasons. Firstly, hospital management teams do not build good partnerships and programmes with society. Moreover, they do not support the charities and social events. Workplace is considered a significant influential factor influencing hospital image. Workplace provides a good opportunity for some Saudi private hospitals to retain a qualified staff, especially in the human resources scarcity problem in the Saudi health labor market. This resulted from the fair salary systems, staff rights, training, honesty, and open door communication. The marketplace is a significant influential factor on hospital image. This result comes out of the neglected manner by hospital management teams towards marketplace, e.g. lack of health service research, and downsizing of new health service development and solutions, in relation to the adoption of accountability during the delivery of health services to target patients. The result shows insignificant influence on hospital image. The reason may be that most private hospital mangers do not consider the elements of accountability as a crucial factor influencing hospital image.

\section{Research Recommendations}

The hospital vision needs enhanced by adopting the code of medical ethics, and the vision which represents the hospital value and culture needs to be executed. This will help hospitals to improve their image in society. Engaging in the building and maintenance of valuable ongoing collaborative relationships with the hospital stakeholders by building partnerships with them is essential, as is adopting some of the social activities, e.g. sports and medical campaigns (such as mammogram scanning).It is important also to adopt retention policies for hospital staff by paying fair salaries, offering training courses and annual leave, etc., shedding light on improving marketplace relations. As such, hospital managers must investigate their patients' personal needs and wants in order to become aware of the domestic competitors. Finally, regarding accountability, Saudi hospitals should start applying medical negligence responsibility and transparency while delivering their health services to the target market.

\section{References}

Ambastha, A., \& Momaya, K. (2004). Competitiveness of Firms: Review of Theory, Frameworks and Models. Singapore Management Review, 26(1), 45-61.

Carroll, A. B. (1999). Corporate Social Responsibility. Business and Society, 38(3), 268-295. http://dx.doi.org/10.1177/000765039903800303

Carter, A. B., Betty, J. S., \& Simpson, W. (2003). Corporate Governance, Board Diversity, and Firm Value. The Financial Review, 38, 33-53. http://dx.doi.org/10.1111/1540-6288.00034

Chand, M., \& Fraser, S. (2006). The Relationship between Corporate Social Performance and Corporate Financial Performance: Industry Type as a Boundary Condition. The Business Review, Cambridge, 5(1), 240-245.

Donaldson, T., \& Dunfee, T. W. (2002). Ties that Bind in Business Ethics: Social Contracts and Why they Matter. Journal of Banking \& Finance, 26(9), 1853-1865. http://dx.doi.org/10.1016/S0378-4266(02)00195-4

European Commission (EC). (2002). Green Book: Promoting a European Framework for Corporate Social Responsibility. http://europa.eu.int/comm/employment_social/socdial/csr/greenpaper.htm.

Freeman, R. (1999). Divergent Stakeholder Theory. Academy of Management Review 24(2), 233-236. http://dx.doi.org/10.5465/amr.1999.1893932

Freeman, R. E., \& Evan, W. M. (1990). Corporate Governance: A Stakeholder Interpretation. Journal of Behavioural Economics, 19(4), 337-359. http://dx.doi.org/10.1016/0090-5720(90)90022-Y

International Labor Organization. (2007). Fundamental Principles and Rights to Work. http://www.ilo.org/dyn/declaris/ DECLARATIONWEB.INDEXPAGE.

Kakabadse, N., \& Rozuel, C. (2006). Meaning of corporate social responsibility in a local French hospital: a case study. Society and Business Review, 1(1), 77-96. http://dx.doi.org/10.1108/17465680610643364

Lowell, B. (2007). The New Metrics of Corporate Performance: Profit Per Employee. The McKinsey Quarterly, 1, 56-65. www.mckinseyquarterly.com

Lozano, J. (2002). Towards the Relational Corporation: From Managing Stakeholder Relations to Building Stakeholder Relationships (Waiting for Copernicus). Corporate Governance, 5(2), 60-77. http://dx.doi.org/10.1108/14720700510562668

McWilliams, A., \& Siegel, D. (2001). Corporate Social Responsibility: A Theory of the Firm Perspective. Academy of Management Review, 26(1), 117-128.

Porter, M. E., \& Kramer, M. R. (2006). Strategy and Society: The Link Between Competitive Advantage and Corporate 
Social Responsibility. Harvard Business Review, 84(12), 78-92.

Rohini, R., \& Mahadevappa, M. (2010). Social responsibility of hospitals: an Indian Context, Social Responsibility Journal, 6(2), 268-285. http://dx.doi.org/10.1108/17471111011051766

Smith, N. (2003). Corporate Social Responsibility: Whether or How? California Management Review, 45(4), 52-76. http://dx.doi.org/10.2307/41166188

Solomon, R. C. (1993). Ethics and Excellence.Cooperation and Integrity in Business. Oxford: Oxford University Press.

Stewart, T. A. (2006). Corporate Social Responsibility: Getting the Logic Right. Harvard Business Review, 84(12), 14.

Swanson, D. L. (1995). Addressing a Theoretical Problem by Reorienting the Corporate Social Performance Model. Academy of Management Review, 20, 43-64.

Tuan, L. (2013). The role of CSR in clinical governance and its influence on knowledge sharing. Clinical Governance: An International Journal, 18(2), 90-113. http://dx.doi.org/10.1108/14777271311317891

Valor, C. (2005). Corporate Social Responsibility and Corporate Citizenship: Towards Corporate Accountability. Business and Society Review, 110(2), 191-213. http://dx.doi.org/10.1111/j.0045-3609.2005.00011.x

Vilanova, M., Lozano, J., \& Arenas, D. (2009). Exploring the Nature of the Relationship between CSR and Competitiveness. Journal of Business Ethics, 87, 57-69. http://dx.doi.org/10.1007/s10551-008-9812-2

Waddock, S. (2000). The Multiple Bottom Lines of Corporate Citizenship: Social Investing, Reputation, and Responsibility Audits. Business \& Society Review, 105(3), 323-346. http://dx.doi.org/10.1111/0045-3609.00085

Whetten, D. A., Rands, G., \& Godfrey, P. (2001). What are the Responsibilities of Business in Society? In A Pettigrew.

Zadek, S. (2001). The Civil Corporation: the New Economy of Corporate Citizenship. London: Earth scan.

\section{Copyrights}

Copyright for this article is retained by the author(s), with first publication rights granted to the journal.

This is an open-access article distributed under the terms and conditions of the Creative Commons Attribution license (http://creativecommons.org/licenses/by/4.0/). 